\title{
Experience of 16 years and its associated challenges in the Field Epidemiology Training Program in Korea
}

\author{
Moo-Sik Lee', Eun-Young Kim'1, Sang-Won Lee ${ }^{2}$ \\ 'Department of Preventive Medicine, Konyang University College of Medicine, Daejeon, Korea; ${ }^{2}$ Division of Public Health Preparedness and \\ Response, Centers for Disease Control and Prevention, Cheongju, Korea
}

OBJECTIVES: The field epidemiologist system of South Korea, which employs public health doctors who are relatively more readily available, was created in 1999 to ensure a ready supply of experts for epidemiological investigations and enable an effective response for new and reemerging infectious diseases. However, the 2015 outbreak of Middle East Respiratory Syndrome revealed limitations in the existing systems of management of field epidemiologists and communicable diseases.

METHODS: The present study aims to evaluate data on current states, administrative reports, and other literature on the field epidemiologist system that has been in place in South Korea for 16 years since 1999 and to suggest appropriate future improvements in this system.

RESULTS: By suggesting methods to evaluate the field epidemiologist system and training programs and by suggesting ways for the Korea Centers for Disease Control and Prevention to conduct evaluations on its own, the present study provides supporting evidence for improvement of systems for training of experts in epidemiological investigations. Moreover, based on the findings, this study also suggests methods to systematically train experts in communicable diseases management and a sustainable system to establish the basis of and develop strategies for a systematic and phased management of field epidemiologist training programs.

CONCLUSIONS: The present study suggests the possibility of establishing dedicated training facilities, revising the guidelines on training and improvement of the competency of public health experts, while not limiting the scope of application to communicable diseases.

KEY WORDS: Epidemiological investigations, Infectious diseases, Middle East Respiratory Syndrome, Korea

\section{INTRODUCTION}

In the case of outbreaks of infectious diseases, it is imperative to find sources of infection through timely epidemiological investigations and to establish an appropriate prevention method based on the results of the investigations. However, inadequate initial

\section{Correspondence: Moo-Sik Lee}

Department of Preventive Medicine, Konyang University College of Medicine, 158 Gwanjeodong-ro, Seo-gu, Daejeon 35365, Korea E-mail: mslee@konyang.ac.kr

Received: Jul 24, 2017 / Accepted: Dec 22, 2017 / Published: Dec 25, 2017

This article is available from: http://e-epih.org/

(C) This is an open-access article distributed under the terms of the Creative Commons Attribution License (http://creativecommons.org/licenses/by/4.0/), which permits unrestricted use, distribution, and reproduction in any medium, provided the original work is properly cited.

(C) 2017, Korean Society of Epidemiology epidemiological investigations sometimes lead to an inability to elucidate the causes of the spreading of infectious diseases and to establish clear disease prevention strategies as well as strategies to prevent recurrence. For timely prevention, it is necessary to find the sources and routes of infection through prompt epidemiological investigations in the initial stages of outbreak. To do this, the availability of epidemiology experts in infectious diseases and staff dedicated to infectious diseases is the most crucial factor [1]. Nevertheless, South Korea (hereafter Korea) currently lacks experienced field epidemiologists who have an adequate understanding of epidemiology of infectious diseases [2].

The expertise of field epidemiologists requires sufficient field data and an ability to make epidemiological judgments for making decisions relating to public health [3]. In the last Middle East Respiratory Syndrome (MERS) outbreak in May 2015 criticism on the lack of field epidemiologists available to conduct epidemiological investigations in emergency situations and the lack of con- 
tinuity and expertise in epidemiological investigations gained support [4]. The Act on the Prevention and Management of Infectious Diseases, which aims to improve adequacy in the existing infectious disease management system revealed through the MERS outbreak, has been revised in part on July 6, 2015; the revisions include increases in the number and authority of field epidemiologists [5].

Therefore, the present paper aims to review the current Korean field epidemiologist system and training programs that seek to improve the competency of field epidemiologists.

\section{MATERIALS AND METHODS}

This study aims to evaluate data on current states, administrative reports (included planning data, periodic and final reports, and evaluation reports of Korea field epidemiology training programs [KFETP], focus group interview and questionnaire survey), and other literature on the field epidemiologist management system that has been in place in Korea for 16 years since 1999, also seeks to suggest aspects that should be challenged in the future, and to suggest appropriate future improvements in this system. All tables were created from internal data of Korea Centers for Disease Control and Prevention (KCDC) and KFETP.

\section{RESULTS}

\section{Introduction of Korean Field Epidemiology Training Programs (KFETP) \\ History of KFETP}

The Chosun Rules on Committee for Infectious and Endemic Diseases established in 1920 (29th government general ordinance, July 14,1920 ) included rules on the establishment and management of an epidemiological investigation bureau that functioned similarly to the present-day field epidemiologists [6-8]. The Law for the Prevention of Communicable Diseases, which was enacted as the 308th Law on February 2, 1954, established legal systems on Korea's management of infectious diseases. The law was fully enforced when the enforced ordinance for the law was enacted on February 28, 1957 [6]. As part of the Research Project on the Training and Development of Experts in Infectious Diseases and Staff for Infectious Disease Management, which was established in 1999 to conduct research on precautions against newly emerging and reemerging infectious diseases, the field epidemiologist system was set in place. Initially, 19 public health practitioners were selected to receive 2 weeks of introductory education and were deployed at the Korea National Institute of Health (KNIH) and in each city and province; these epidemiologists were employed for 1 year for epidemiological investigations of infectious diseases. This was part of a pilot project, which employed public health practitioners who were relatively more available to effectively respond to new and reemerging infectious diseases by ensuring an available supply of experts in epidemiological investigations. In 2000, the Field Epidemiology Training Program (FETP), a training pro- gram focusing on field epidemiological investigations, was newly created. For the program, public health practitioners interested in epidemiology and infectious diseases were selected to become field epidemiologists who would be responsible for epidemiological investigations and surveillance of infectious diseases for at least 2 years. After 4 weeks of introductory training for field epidemiologists, the epidemiologists were deployed at the $\mathrm{KNIH}$ and in each city and province to conduct epidemiological investigations and surveillance of various infectious diseases [1].

On December 29, 2001, supporting evidence for national aid on the costs of training and education of field epidemiologists and on the investigation of adverse reactions to vaccines was prepared, and epidemiological investigations were subsequently systematized. Multiple revisions have been made since then, and the law was fully revised to the Law on Prevention and Management of Infectious Diseases to improve on problems in infectious disease management revealed during the 2009 outbreak of novel swineorigin influenza A (H1N1) [6]. The law was further improved in part on July 6,2015 , to improve on the issues found during the MERS outbreak in May 2015 [5].

\section{Purpose of KFETP}

The Centers for Disease Control and Prevention (CDC) defines FETP as an epidemiology and public health training and service program that establishes public health systems to improve sustainable public health competencies [9]. The KFETP has not been defined with ultimate aims as done by the CDC. However, the Rules on the Management of KCDC Field Epidemiologists states that the KFETP refers to a 2-year program, which includes introductory training for new field epidemiologists who will be appointed by the director of KCDC, mayors, or governors (less than $120 \mathrm{hr} /$ yr) and on-the-job training focusing on case studies provided to already appointed field epidemiologists (less than $50 \mathrm{hr} / \mathrm{yr}$ ), according to Article 60 of the Law on Prevention and Management of Infectious Diseases [10]. Moreover, the purpose of FETP suggested in the 2015 project guidelines on the management of infectious diseases states that the FETP aims to enable field epidemiologists to conduct professional and active investigations in outbreaks by helping them acquire professional knowledge required for the improvement of field epidemiologist competencies and management of infectious diseases; to provide new knowledge and information on infectious diseases to field epidemiologists; and to improve expertise in epidemiological investigations through exchange of field experiences in epidemiological investigations [11].

\section{Current states, past experiences, and achievements of KFETP \\ Selection of field epidemiologists}

Based on Article 26 of the enforced ordinance on the Law on Prevention and Management of Infectious Diseases, the Minister of Health and Welfare, mayors of each city, or governors of each province appoint field epidemiologists. The qualifications for field epidemiologists as specified by law include civil servants responsi- 
Table 1. Epidemic Intelligence Service officers'specialties of Korea, 1999-2015

\begin{tabular}{|c|c|c|c|c|c|c|c|c|c|c|c|c|c|c|c|c|c|c|c|}
\hline Location & Specialty & 1999 & 2000 & 2001 & 2002 & 2003 & 2004 & 2005 & 2006 & 2007 & 2008 & 82009 & 2010 & 2011 & 2012 & 2013 & 32014 & 42015 & Total \\
\hline \multirow[t]{8}{*}{ Central } & Internal medicine & 2 & 2 & 2 & 3 & 1 & 3 & & & & & & & & 1 & & & 2 & 16 \\
\hline & Pediatrics & 1 & & & 1 & 1 & & 1 & 1 & 2 & 2 & 1 & 3 & & 2 & 1 & 1 & & 17 \\
\hline & Family medicine & & & & 1 & & & 2 & 1 & 2 & 1 & & 1 & & & & & & 8 \\
\hline & Preventive medicine & & 1 & & & & & & & & & & & 3 & & & & & 4 \\
\hline & Neurology & & & & & & & 1 & & & 1 & & 2 & & 1 & 2 & 1 & 2 & 10 \\
\hline & $\begin{array}{l}\text { Occupational and environ- } \\
\text { mental medicine }\end{array}$ & & & & & & & & & 1 & & & 2 & & & 1 & 1 & & 5 \\
\hline & Other specialty ${ }^{1}$ & 1 & 1 & 1 & & & & & & & & & & & 1 & 2 & & & 6 \\
\hline & Subtotal & 4 & 4 & 3 & 5 & 2 & 3 & 4 & 2 & 5 & 4 & 1 & 8 & 3 & 5 & 6 & 3 & 4 & 66 \\
\hline \multirow{10}{*}{$\begin{array}{l}\text { Provin- } \\
\text { cial }\end{array}$} & Internal medicine & 4 & 4 & 3 & 15 & 9 & 10 & 11 & 9 & 6 & 5 & 7 & 4 & 2 & & 2 & 4 & 4 & 99 \\
\hline & Pediatrics & & & & & & 1 & 1 & 2 & 2 & 2 & 1 & 4 & & & 2 & 1 & 1 & 17 \\
\hline & Family medicine & & & & & 1 & & & 2 & 1 & 2 & & & 1 & & & & & 7 \\
\hline & Preventive medicine & & 1 & & 1 & & & & & & & & & & & & & & 2 \\
\hline & Neurology & & 1 & & & & & & & & & & & & & 1 & 2 & 1 & 5 \\
\hline & $\begin{array}{l}\text { Occupational and environ- } \\
\text { mental medicine }\end{array}$ & & & & & & & & & & & & & & & 1 & & & 1 \\
\hline & Other specialty ${ }^{2}$ & 3 & 2 & & 1 & 1 & & 2 & & 1 & 1 & 2 & & 1 & 3 & 4 & 1 & 2 & 24 \\
\hline & General practitioner & & & & 1 & & & 1 & & 1 & & & 3 & 2 & 4 & 1 & 1 & 1 & 15 \\
\hline & No information & 7 & 7 & 4 & & & & & & & & & & 1 & & & & & 19 \\
\hline & Subtotal & 14 & 15 & 7 & 18 & 11 & 11 & 15 & 13 & 11 & 10 & 10 & 11 & 6 & 8 & 11 & 9 & 9 & 189 \\
\hline Total & & 18 & 19 & 10 & 23 & 13 & 14 & 19 & 15 & 16 & 14 & 11 & 19 & 9 & 13 & 17 & 12 & 13 & 255 \\
\hline
\end{tabular}

Unit: persons.

'Other specialty in central government: laboratory medicine, urology, obstetrics and gynecology, pathology etc.

2Other specialty in provincial government: anesthesiology, urology, obstetrics and gynecology, thoracic surgery, radiology, orthopedics, rehabilitation medicine, surgery, ear, nose and throat, dermatology, ophthalmology, etc.

ble for epidemiological investigations, disease prevention, or vaccination; public health practitioners employed according to the Special Law for Public Health in Rural Communities; medical practitioners as specified by Article 2 Clause 1 of the Medical Service Law; and other experts in fields pertaining to infectious diseases. Field epidemiologists are selected from those that qualify according to the above criteria [5]. Table 1 shows the specialties of field epidemiologists employed between 1999 and 2015 which were created from internal data of KCDC.

\section{Training program and contents}

The KFETP, which is a 2-year-long program, consists of 1 introductory course (3 weeks), workshops (1/yr), on-the-job training (2/yr, 3 days each), and conferences for field epidemiologists (Table 2). Among public health practitioners selected and deployed as new field epidemiologists, licensed medical practitioners responsible for epidemiological investigations, civil servants responsible for disease prevention, epidemiological investigations, and vaccination, and experts in areas related to infectious diseases, those that wish to be trained are selected for the introductory course, which consists of a 3-week-long training on the acquisition of basic knowledge and techniques for epidemiology and infectious disease management. Workshops are conducted between the introductory course and on-the-job training and aim to form networks between newly appointed and experienced field epidemi- ologists and to promote discussions on the field epidemiologist system. The on-the-job trainings are conducted in September and March for central, municipal, and provincial field epidemiologists and for epidemiological investigation staff at quarantine centers and in each city and province. The trainings focus on epidemiological investigation cases to promote acquisition of expert knowledge in smaller projects and discussion of epidemiological investigation cases. Conferences for field epidemiologists are conducted separately during the Fall Conference for the Korean Society of Epidemiology owing to a memorandum of understanding (MOU signed with the society; these conferences aim to investigate cases of epidemiological investigation and to promote presentation and discussion of studies on the characteristics of infectious diseases $[2,11]$.

\section{Courses for introductory and on-the-job training}

The introductory training consists of the following 6 categories (Table 3): epidemiology and statistics of infectious diseases, waterborne and foodborne diseases, diseases for vaccination, responses to public health crisis, epidemiological investigations of other infectious diseases, and administrative measures. The on-the-job training consists of the 4 categories of methodologies of epidemiological research, epidemiology and statistics of infectious diseases, case discussion, and improvement of competency (Table 4). Courses in each category are determined through discussion of 
Table 2. Field epidemiology training program courses in Korea

\begin{tabular}{|c|c|c|c|}
\hline Programs & Duration & Date & Contents \\
\hline \multicolumn{4}{|l|}{ During the 1 st year } \\
\hline Introductory course & 3 wk & April - May & $\begin{array}{l}\text { Acquisition of basic knowledge and techniques for epidemiology and infectious disease } \\
\text { management }\end{array}$ \\
\hline Workshop & $2 d$ & July & Discussion of improvements for the field epidemiologist system \\
\hline First on-the-job training & $3 d$ & September & $\begin{array}{l}\text { Sharing of experiences and knowledge gained through actual investigations and in-depth } \\
\text { analysis and training on epidemiological investigations of infectious diseases }\end{array}$ \\
\hline Second on-the-job training & $3 d$ & December & $\begin{array}{l}\text { Sharing of experiences and knowledge gained through actual investigations and in-depth } \\
\text { analysis and training on epidemiological investigations of infectious diseases }\end{array}$ \\
\hline Conference & $1 \mathrm{~d}$ & February & Sharing of results and related information of epidemiological investigations \\
\hline Grand rounds & $1 / \mathrm{mo}$ & Every month & Analysis of current outbreaks of infectious diseases and epidemiological investigation cases \\
\hline \multicolumn{4}{|l|}{ During the 2nd year } \\
\hline Workshop & $2 d$ & July & Discussion of improvements for the field epidemiologist system \\
\hline First on-the-job training & $3 d$ & September & $\begin{array}{l}\text { Sharing of experiences and knowledge gained through actual investigations and in-depth } \\
\text { analysis and training on epidemiological investigations of infectious diseases }\end{array}$ \\
\hline Second on-the-job training & $3 d$ & December & $\begin{array}{l}\text { Sharing of experiences and knowledge gained through actual investigations and in-depth } \\
\text { analysis and training on epidemiological investigations of infectious diseases }\end{array}$ \\
\hline Conference & $1 \mathrm{~d}$ & February & Sharing of results and related information of epidemiological investigations \\
\hline Grand rounds & $1 / \mathrm{mo}$ & Every month & Analysis of current outbreaks of infectious diseases and epidemiological investigation cases \\
\hline
\end{tabular}

contracted educators and KCDC conducted before each training session [2].

\section{Areas of activities of field epidemiologists}

Based on Article 26 Clause 2 of the enforced ordinance for the Law on the Prevention and Management of Infectious Diseases, the tasks of field epidemiologists are as follows: [12].

- Establishment of plans for epidemiological investigations

- Administration and analysis of epidemiological investigations

- Development of the criteria and methods of epidemiological investigations

- Training on techniques for epidemiological investigations

- Education and training on epidemiological investigations

- Epidemiological research on infectious diseases

Korean field epidemiologists play an important role in managing infectious diseases while conducting the tasks outlined by law as below: [13].

- In outbreaks or epidemics of infectious diseases, field epidemiologists conduct investigations in cooperation with the central government and municipal, county and district disease prevention agencies.

- In outbreaks or cases of eradicated infectious diseases, such as measles, field epidemiologists conduct case and epidemiological investigations.

- In outbreaks or cases of adverse reactions to vaccination, field epidemiologists conduct case and epidemiological investigations.

-When diseases that are not indigenous to Korea (e.g., Plasmodium falciparum malaria) are introduced from overseas, field epidemiologists conduct case investigations.

Moreover, field epidemiologists also play a significant role in national crises involving infectious diseases $[13,14]$ : Investigation of measles epidemic and epidemiological investigation of adverse reactions to vaccination in 2000-2001; Case investigation of cholera and anthrax hoax terror in 2001; Case investigations during the severe acute respiratory syndrome epidemic in 2003; Case investigations of people that came into contact with $\mathrm{AI}$ during $\mathrm{AI}$ epidemics since 2003; Case and epidemic investigation during the H1N1 epidemic in 2009; Case and epidemic investigation during the MERS epidemic in 2015 (Table 5).

After retirement, field epidemiologists also act as educators in FETP, sharing information and their experiences with a sense of duty.

\section{Academic outcomes of field epidemiologists}

Since 2010, training programs have been revised to improve the quality of education provided to field epidemiologists; as a result, field epidemiologists are now required to prepare and present at least 1 paper per year through conferences. The data collected through field epidemiologist activities are analyzed and orally presented at the conference held in the second year of the training program, and 6 to 8 academic research papers are published every year. However, academic activities are mostly conducted by central field epidemiologists, and not many field epidemiologists deployed at municipal or provincial levels are involved in academic activities.

\section{Mentorship program between field epidemiologists}

In 2000, an advising professor system involving professors that lead field training from the start of FETP was planned, but the system was not managed properly [15]. For field epidemiologists working at the KCDC, multiple experts in related areas working in the same department can advise on performance of tasks and learn- 


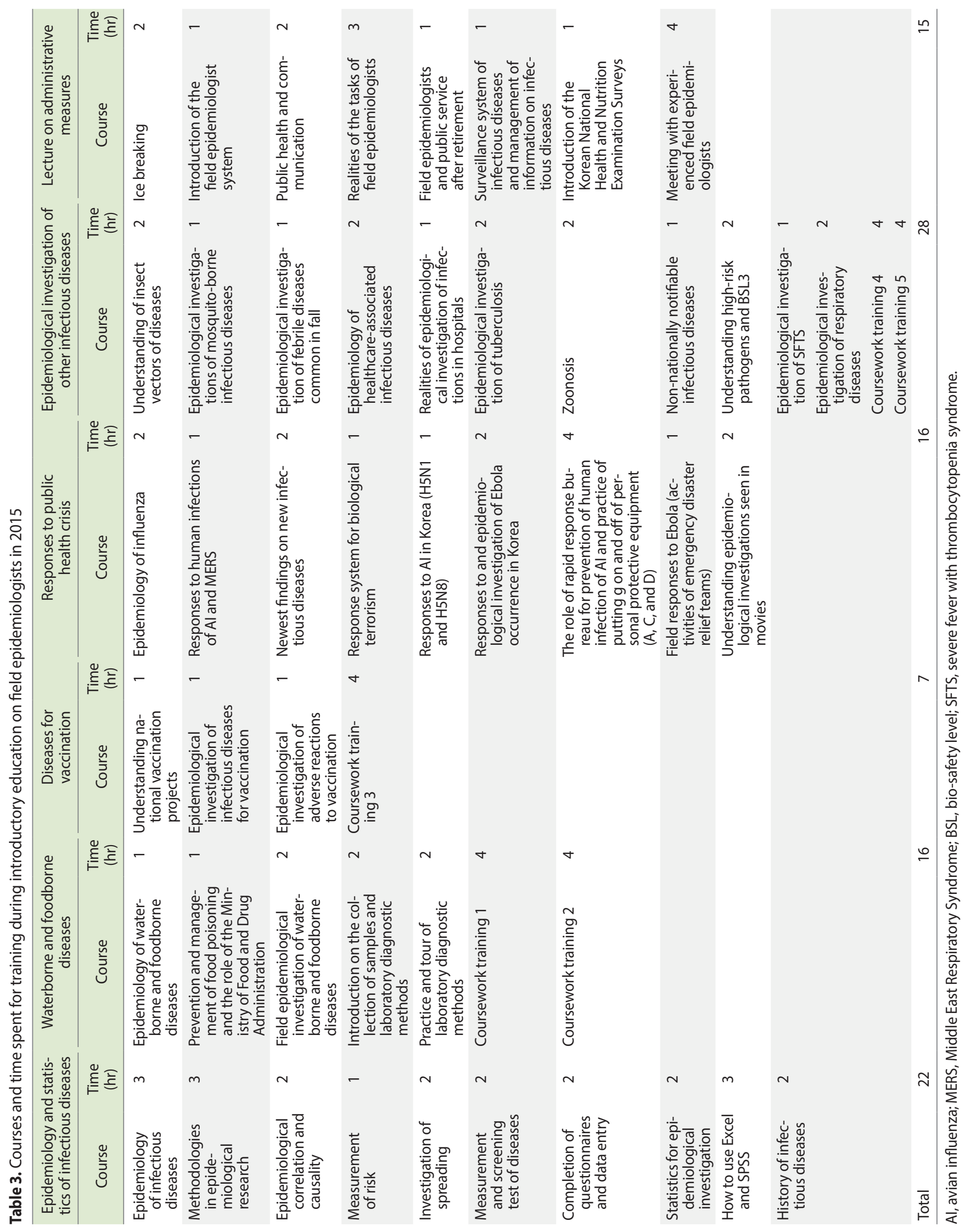


Table 4. Courses and time spent for training during on-the-job training for field epidemiologists in 2015

\begin{tabular}{|c|c|c|c|c|c|c|c|c|}
\hline \multicolumn{3}{|c|}{ First on-the-job training } & \multicolumn{3}{|c|}{ Second on-the-job training } & \multicolumn{3}{|c|}{ Third on-the-job training } \\
\hline Category & Course & $\begin{array}{c}\text { Time } \\
(\mathrm{hr})\end{array}$ & Category & Course & $\begin{array}{c}\text { Time } \\
(\mathrm{hr})\end{array}$ & Category & Course & $\begin{array}{l}\text { Time } \\
\text { (hr) }\end{array}$ \\
\hline \multirow[t]{3}{*}{$\begin{array}{l}\text { Epidemiology } \\
\text { of infectious } \\
\text { diseases }\end{array}$} & $\begin{array}{l}\text { Case report of major epi- } \\
\text { demiological investiga- } \\
\text { tions of MERS outbreak: } \\
\text { cases with uncertain } \\
\text { routes of infection }\end{array}$ & 1.0 & $\begin{array}{l}\text { Methodologies } \\
\text { in epidemio- } \\
\text { logical research }\end{array}$ & $\begin{array}{l}\text { Revisions of pertussis } \\
\text { guidelines }\end{array}$ & 2.0 & $\begin{array}{l}\text { Methodolo- } \\
\text { gies in epi- } \\
\text { demiological } \\
\text { research }\end{array}$ & $\begin{array}{l}\text { Distribution of incubation } \\
\text { period for infectious } \\
\text { diseases and estimation } \\
\text { and modeling of com- } \\
\text { mon exposure }\end{array}$ & 2.5 \\
\hline & $\begin{array}{l}\text { Case report of major epi- } \\
\text { demiological investiga- } \\
\text { tions of MERS outbreak: } \\
\text { cases with long incuba- } \\
\text { tion periods }\end{array}$ & 1.0 & $\begin{array}{l}\text { Epidemiology } \\
\text { of infectious } \\
\text { diseases }\end{array}$ & $\begin{array}{l}\text { Management of latent } \\
\text { tuberculosis }\end{array}$ & 1.0 & & R statistics and graphs & 2.5 \\
\hline & $\begin{array}{l}\text { Public health practition- } \\
\text { ers and new infectious } \\
\text { diseases }\end{array}$ & 1.0 & $\begin{array}{l}\text { Discussion of } \\
\text { cases }\end{array}$ & Review of MERS manual & 2.0 & & $\begin{array}{l}\text { Preparation of manu- } \\
\text { scripts in English for } \\
\text { field epidemiologist }\end{array}$ & 2.5 \\
\hline $\begin{array}{l}\text { Discussion of } \\
\text { cases }\end{array}$ & $\begin{array}{l}\text { Discussion of future } \\
\text { responses for sporadic } \\
\text { occurrences of MERS }\end{array}$ & 1.0 & & Review of the Al manual & 2.0 & $\begin{array}{l}\text { Discussion of } \\
\text { cases }\end{array}$ & $\begin{array}{l}\text { Discussion for improve- } \\
\text { ment of the field epide- } \\
\text { miologist system }\end{array}$ & 0.5 \\
\hline \multirow[t]{5}{*}{$\begin{array}{l}\text { Improvement } \\
\text { of competen- } \\
\text { cies }\end{array}$} & $\begin{array}{l}\text { Discussion of findings of } \\
\text { MERS-related epidemio- } \\
\text { logical investigations }\end{array}$ & 2.0 & & $\begin{array}{l}\text { Review of the Ebola } \\
\text { manual }\end{array}$ & 2.0 & $\begin{array}{l}\text { Improvement } \\
\text { of compe- } \\
\text { tencies }\end{array}$ & EOC in Korea & 0.5 \\
\hline & & & & $\begin{array}{l}\text { Discussion for improve- } \\
\text { ment of the field epi- } \\
\text { demiologist system }\end{array}$ & 5.0 & & $\begin{array}{l}\text { Post-MERS measures from } \\
\text { the Korean Medical As- } \\
\text { sociation }\end{array}$ & 2.5 \\
\hline & & & $\begin{array}{l}\text { Improvement of } \\
\text { competencies }\end{array}$ & $\begin{array}{l}\text { Revisions of pertussis } \\
\text { guidelines }\end{array}$ & 2.0 & & $\begin{array}{l}\text { Doctors and KCDC seen } \\
\text { through the media }\end{array}$ & 2.5 \\
\hline & & & & & & & $\begin{array}{l}\text { Field epidemiologist sys- } \\
\text { tems, such as EIS, FETP, } \\
\text { and CSTE }\end{array}$ & 1.0 \\
\hline & & & & & & & $\begin{array}{l}\text { Evaluative tests for on- } \\
\text { the-job training }\end{array}$ & 0.5 \\
\hline Total & & 6.0 & & & 16.0 & & & 15.0 \\
\hline
\end{tabular}

Al, avian influenza; EOC, Emergency Operations Center; EIS, Epidemic Intelligence Service; FETP, Field Epidemiology Training Program; CSTE, Council of State and Territorial Epidemiologists; MERS, Middle East Respiratory Syndrome; KCDC, Korea Centers for Disease Control and Prevention.

Table 5. Major outcomes of field epidemiologists by the year

\begin{tabular}{|c|c|c|c|}
\hline Year & Disease & Region & Investigation (No. of patients) \\
\hline 2000 & Malaria & National & Outbreak $(32,647)$ \\
\hline 2001 & Cholera & Goseong & Outbreak (18) \\
\hline 2003 & Severe acute respiratory syndrome & National & Suspected case \\
\hline 2004 & Hepatitis A virus & Gongju & Outbreak (105) \\
\hline 2005 & Avian influenza virus & National & High risk group \\
\hline 2006 & Shigellosis & Sancheong & Outbreak (198) \\
\hline \multirow[t]{2}{*}{2007} & Falciparum malaria & Busan & Confirmed case \\
\hline & Human monkey pox & Seoul & Suspected case \\
\hline 2008 & Norovirus & Churwon & Outbreak (625) \\
\hline \multirow[t]{2}{*}{2009} & Pandemic influenza A (H1N1) & National & Outbreak $(>100,000)$ \\
\hline & Hepatitis A virus & Seoul & Outbreak (33) \\
\hline 2010 & Hepatitis A virus & Inje & Outbreak (44) \\
\hline 2011 & Humidifier disinfectant lung injury & National & Outbreak (>100) \\
\hline \multirow[t]{2}{*}{2012} & Pertussis & Yeongam & Outbreak (154) \\
\hline & Lyme disease & Hwacheon & Confirmed case \\
\hline 2015 & Middle East Respiratory Syndrome & National & Outbreak (186) \\
\hline
\end{tabular}


ing. However, since municipal and provincial field epidemiologists lack field experts who can provide training, they lack proper field training [2].

A one-on-one advising professor system for municipal and provincial field epidemiologists was implemented in 2014 upon signing of an MOU between the KCDC and the Korean Society of Epidemiology, which resulted in recommendations of professors from the Korean Society of Epidemiology. However, the system was conducted only in 2014, and no progress has been made since then. The system encouraged cities and provinces to voluntarily host epidemiological investigation task advisory meetings at least 3 times a year to enable field epidemiologists to directly receive advice on tasks from advising professors. The professors provided reviews and instructions on field epidemiological investigation results conducted by municipal and provincial epidemiologists; guidance on epidemiological investigation and research directions on nationally notifiable infectious diseases occurring in each city or province; and guidance on conference reports and publications of epidemiological investigation results [2,15].

\section{Evaluation of KFETP}

KFETP are evaluated in terms of the management of training and training curricula. For the evaluation of the management of training, the KCDC and universities contracted for training hold meetings to evaluate each training phase [2]. When 1-year-long training programs are completed, a meeting for overall evaluation is hosted to provide feedback on the evaluation procedure and results such that the feedback can be reflected in the following year's training plans. For evaluation of training curricula, trainees are evaluated through tests on their knowledge and practical skills acquired during the training. Moreover, they are surveyed on their satisfaction with the training program in terms of planning of training, operation of training, training media and environment, and training outcomes. The trainees also evaluate the curricula and lecturers [2].

Table 6. Evaluation results of competencies before and after field epidemiology training program in 2016

\begin{tabular}{|c|c|c|c|c|c|c|}
\hline \multirow{2}{*}{ Description of each competency } & \multirow{2}{*}{$\mathrm{n}$} & \multicolumn{2}{|c|}{ Mean } & \multirow{2}{*}{$\begin{array}{c}\text { Mean } \\
\text { difference }\end{array}$} & \multirow{2}{*}{$\begin{array}{l}\text { Standard error } \\
\text { of difference }\end{array}$} & \multirow{2}{*}{$\mathrm{p}$-value } \\
\hline & & Before & After & & & \\
\hline \multicolumn{7}{|l|}{ Epidemiological method } \\
\hline $\begin{array}{l}\text { I can use epidemiological methods in conducting research to } \\
\text { improve public health programs. }\end{array}$ & 26 & 1.58 & 2.08 & -0.50 & 0.71 & 0.001 \\
\hline I can respond to epidemics of diseases & 26 & 1.46 & 2.12 & -0.66 & 0.69 & $<0.001$ \\
\hline \multicolumn{7}{|l|}{ Statistics } \\
\hline $\begin{array}{l}\text { I can analyze epidemiological data using appropriate statisti- } \\
\text { cal methods }\end{array}$ & 26 & 1.54 & 2.08 & -0.54 & 0.76 & 0.001 \\
\hline \multicolumn{7}{|l|}{ Public health surveillance } \\
\hline I can manage public health surveillance systems & 26 & 1.46 & 2.08 & -0.62 & 0.64 & $<0.001$ \\
\hline \multicolumn{7}{|l|}{ Experiment and safety } \\
\hline $\begin{array}{l}\text { I can use laboratory resources to support epidemiological } \\
\text { activities }\end{array}$ & 26 & 1.35 & 1.92 & -0.57 & 0.81 & 0.001 \\
\hline \multicolumn{7}{|l|}{ Communication } \\
\hline I can develop documented public health communications & 26 & 1.38 & 2.08 & -0.70 & 0.68 & $<0.001$ \\
\hline I can develop and provide oral public health communications & 26 & 1.46 & 2.08 & -0.62 & 0.64 & $<0.001$ \\
\hline \multicolumn{7}{|l|}{ Computer techniques } \\
\hline I can use computers for special tasks related to public health & 26 & 1.62 & 2.04 & -0.42 & 0.76 & 0.009 \\
\hline \multicolumn{7}{|l|}{ Management and leadership } \\
\hline I can manage field projects & 26 & 1.35 & 2.04 & -0.69 & 0.68 & $<0.001$ \\
\hline I can manage the staff and resources & 26 & 1.50 & 2.04 & -0.54 & 0.71 & 0.001 \\
\hline I can become an effective team leader and member & 26 & 1.46 & 2.04 & -0.58 & 0.64 & $<0.001$ \\
\hline I can manage my own tasks & 26 & 1.62 & 2.23 & -0.61 & 0.64 & $<0.001$ \\
\hline \multicolumn{7}{|l|}{ Preventive effects } \\
\hline I can apply simple tools to analyze economic efficiency & 26 & 1.35 & 1.92 & -0.57 & 0.70 & $<0.001$ \\
\hline \multicolumn{7}{|l|}{ Teaching and mentoring } \\
\hline I can train public health experts & 26 & 1.15 & 1.88 & -0.73 & 0.67 & $<0.001$ \\
\hline I can mentor public health experts & 26 & 1.19 & 2.00 & -0.81 & 0.63 & $<0.001$ \\
\hline \multicolumn{7}{|l|}{ Determination of the order of priority of diseases } \\
\hline $\begin{array}{l}\text { I can evaluate the importance of diseases or national public } \\
\text { health projects and determine the order of priority }\end{array}$ & 26 & 1.42 & 1.96 & -0.54 & 0.71 & 0.001 \\
\hline Total & 26 & 1.43 & 2.04 & -0.61 & 0.52 & $<0.001$ \\
\hline
\end{tabular}




\section{Results of evaluation of competency of field epide- miologists before and after introductory training}

In 2015, an FETP competency evaluation was conducted before and after the introductory training for field epidemiologists. For the FETP competency evaluation, competency suggested by the CDC was translated into Korean and edited accordingly. Ten criteria and 16 items were evaluated. For techniques required for each competency, the trainees evaluated their own level of proficiency in the techniques on a 3-point scale [2]: point 1 refers to simply knowing the concept but lacking techniques to conduct tasks without others' help; point 2 refers to knowing the concept and being able to conduct tasks with limited help from others; and point 3 refers to being able to conduct tasks without others' help, to coach others, and to solve problems in a creative way.

According to evaluation conducted in 2015 before and after the introductory training for field epidemiologists, the scores improved significantly from 1.43 before the training to 2.04 after the training $(\mathrm{p}<0.001)$. The descriptions of each area and competency are shown in Table 6.

\section{DISSCUSSION}

We reviewed and summarized the current states and problems of the Korean field epidemiologist system and future improvements, discussed through focus group interviews (FGI) conducted with experts in preventive medicine and internal medicine in infectious diseases based on review of literature published within and outside of Korea; surveys conducted on experts, field epidemiologists, staff at KCDC, and municipal and provincial civil servants responsible for epidemiological investigation based on the FGI results; and workshops conducted with FETP and Epidemic Intelligence Service experts from CDC and Korean experts and researchers. In particular, the chapter focuses on ways to improve systems to train field epidemiologists; to improve programs for training, education, and evaluation of field epidemiologists; to establish and manage an institution for training; and to plan training of experts in epidemiological investigations from KCDC staff and municipal and provincial civil servants responsible for epidemiological investigation.

\section{Ways to improve systems to train field epidemiologists}

The lack of continuity between expertise and experiences is recognized as the biggest problem in the current system. To recruit more field epidemiologists, it is important to promote occupational security (promotion and compensation), compensation at equal levels as private institutions, cooperation with various overseas institutions performing similar tasks, and field epidemiologists' pride. In addition to compensation, promotion, and welfare, the following should also be implemented to recruit more field epidemiologists: a stable supply through establishment of public medical schools, connection to degree programs, provision of compensation at equal levels as private institutions while also providing high quality training and education, recruitment of experienced professors from private institutes to manage training and education to promote transfer of experienced experts through open positions, and improvement of expertise of field epidemiologists. The following opinions were also noted: exceptions from military service, transition from term system to continued service at related positions in the Ministry of Health and Welfare or KCDC, provision of incentives to field epidemiologists (current and retired), and management of long-term and short-term overseas training programs.

There is a need to improve the sense of duty and suggest future plans for field epidemiologists. First, the scope of work currently limited to infectious diseases should be expanded to chronic and environmental diseases, systematic support for preparation and response to national disasters should be provided, and the sense of duty should be promoted. Second, based on the excellent manpower, techniques, and experiences in Korea, communication with developed and third-world countries should be promoted to expand the scope of work and competency of field epidemiologists to outside of Korea. Third, beyond the term system, which is limited to KCDC, opportunities to work at the Ministry of Health and Welfare and other central government positions should be provided; at the same time, opportunities to work in related public service positions through promotion and transfer should be provided when field epidemiologists meet certain criteria.

It is also necessary to increase the financial compensation for field epidemiologists to a level equal to those at private institutions. Due to the intensifying delays in promotion, it is very difficult to unite civil servants through promotion. When promotion is limited, it is necessary to seek other methods to unite members through other methods of compensation. In such cases, provision of financial incentives is considered most effective; therefore, providing compensation at equal levels to private institutions should be considered. As another alternative, the experienced expert staff system, which was once available for Korean civil servants, can also be used when promotion is delayed due to an oversupply of medical civil servants with equal levels of experiences.

Opportunities for self-improvement should also be provided to field epidemiologists. Overseas training and participation in Korean and overseas conferences should be promoted to encourage continued self-development during employment. As in recruiting long-term employees in the army, medical school students should be recruited through scholarships, military service, degree programs, and preventive medical specialist programs.

Moreover, the current field epidemiologist system employing public health practitioners should also stay in place. Although field epidemiologists do not have to be doctors, epidemiological investigations of cases of infectious diseases require understanding of public health and clinical knowledge as they also involve patients. Thus, major activities and decision making mainly involve doctors. This is why it is difficult to recruit only public health experts in shortages of doctors applying to become field epidemiologists. It is also important to recruit adequate numbers of medical doctor field epidemiologists through allocation of a certain percentage of positions to doctors. 


\section{Improvement of education, training, and evaluation programs for field epidemiologists.}

It is necessary to set core competencies required for Korean field epidemiologists. According to the results of surveys on core competencies, it is necessary to set education and learning goals based on core competencies with consideration of the capabilities and scopes of capabilities required for field epidemiologists and the distribution of diseases in Korea.

Moreover, expert groups or committees to systematically support the field epidemiologist program should be recruited. Such groups or committees should be responsible for the maintenance of the overall quality of the program, development or revision of lectures or case studies in training curricula, and actual training and education of field epidemiologists. Further, an independent pool of dedicated staff or departments should be created to support programs within the KCDC.

Regarding training curricula, introductory and on-the-job training lasts for a total of 5 weeks, which is relatively shorter than FETP conducted overseas. It is necessary to expand the on-the-job training (2-3 days) rather than the introductory training. In particular, the on-the-job training should be expanded to conduct lectures, case studies, and practical training as in introductory training for each required competency. Moreover, since separate training on required core competencies was not provided for epidemiologists with different years of experience, education on core competency should be provided separately for epidemiologists with different experiences. Lectures should be prepared according to core competencies, and lecture time should be distributed accordingly for different core competencies. The time spent for case studies should be increased, and case studies should also be included in on-thejob training. Moreover, review and revision of questionnaires used in coursework training are also required.

In particular, seminars, which were not available previously, should be conducted every week. Since field epidemiologists are deployed at the KCDC and in each municipality and province, online video conferences (weekly) or in-person seminars (weekly or monthly) can be conducted to encourage the epidemiologists to report on their projects and receive guidance and feedback from experts.

For this, it is necessary to invite experts in various areas to conferences. Since some presentations do not involve discussions due to lack of time, this should be improved to enable presenters to receive in-depth guidance and feedback after presentation.

For field training, field managers should be present. The previous advising professor system cannot provide adequate guidance and feedback to trainees. Since experienced epidemiologists who can function as field managers at institutions at which epidemiologists are deployed are lacking, experienced epidemiologists should be encouraged to act as advisors even if they are not deployed at institutions. This would also improve mentorship. Technical advisors and supervisors are also required within institutions; in order for these people to acquire various in-field experiences, administrative support and dedicated staff are required.
For evaluation, criteria and requirement for completion should be made stricter. Moreover, shared parts on multisite FETP reports, completion on epidemiological investigations of epidemics, activities related to surveillance systems, and protocols for planned studies should be evaluated. For periodic evaluation of competency and project progress of field epidemiologists, on-the-job training can be expanded and conducted every 6 months. Evaluations should aim to enable epidemiologists to acquire competencies and complete projects. In other words, systems that can help epidemiologists to complete projects within 2 years should be prepared. Moreover, guidance and feedback are necessary for epidemiologists to complete projects with the help of stronger mentorship. Through the Epi-Aid (epidemiologic assistance) program, completion of projects (e.g., reports on epidemiological investigations of epidemics) should be encouraged.

\section{Plans for establishment of a dedicated training institution for selection and training of field epidemiologists}

The current management of training for field epidemiologists have the following problems: limitations in continuity in education and training, lack of systematic investigation of demands for human resources, inadequate international networking systems, short-term systems for field epidemiologists, and limitations in ensuring a steady supply of human resources owing to field epidemiologists working in clinical areas rather than in public health areas after completion of service terms.

When the causes of the 2015 MERS epidemic were investigated, limitations in experts in field epidemiology, limitations in the current infectious disease management system, lack of field epidemiologists in infectious disease training and response training, and the need for organization and management of other public health human resources were emphasized.

To solve these problems, Korean and overseas experts, field epidemiologists, and researchers agreed that it would be most reasonable to operate a separate "training institute for field epidemiologists" with verified expertise, systematic management, continuous employment of human power (field epidemiologists), and excellence as a training institute.

To implement this in the long run, partial contracted training, which is currently being conducted by the KCDC and Konyang University College of Medicine, should be conducted in the near future. Dedicated staff within the KCDC capable of analyzing and managing such training institutes should then be recruited to form a committee for establishment of the training institute for field epidemiologists, also with the participation of various experts from within and outside of Korea, to train field epidemiologists in a practical manner.

The current Korean field epidemiologist system requires improvements in the system and training program evaluation. Moreover, the KCDC should also conduct its own evaluations to improve the systems to train experts in epidemiological investigations. Further, systematic methods for training experts in the 
management of infectious diseases, developing a basis for systematic and phased operation of FETP, and sustainable systems for development of strategies should be established. It is also necessary to revise the guidelines on training and improvement of the competency of experts in public health, and to establish dedicated training facilities.

\section{CONFLICT OF INTEREST}

The authors have no conflicts of interest to declare for this study.

\section{SUPPLEMENTARY MATERIAL}

Supplementary material (Korean version) is available at http:// www.e-epih.org/.

\section{ORCID}

Moo-Sik Lee: https://orcid.org/0000-0003-1642-701X; EunYoung Kim: https://orcid.org/0000-0002-0163-1117; Sang-Won Lee: https://orcid.org/0000-0002-5384-6785

\section{REFERENCES}

1. Han HW, Go WY, Lee HJ, Kim SS, Kim DG, Bang JH, et al. Development of educational book for Korea field epidemiologist 2003 [cited 2017 Sep 6]. Available from: http://www.cdc.go.kr/CDC/ cms/content/mobile/97/997_view.html (Korean).

2. Lee MS. Final report for Korea field epidemiology training program, 2014. Daejeon: Konyang University; 2015, p. 1-200 (Korean).

3. Thacker SB, Dannenberg AL, Hamilton DH. Epidemic intelligence service of the Centers for Disease Control and Prevention: 50 years of training and service in applied epidemiology. Am J Epidemiol 2001;154:985-992.

4. Kim BG. News on field epidemiologists. Yonhap News Agency; 2015 Jun 26 [cited 2017 May 1]. Available from: http://www.yonhapnews.co.kr/bulletin/2015/06/26/0200000000AKR201506260 73000017.HTML?from = search (Korean).

5. National Law Information Center. Act for Prevention and Con- trol of Communicable Disease; 2015 [cited 2017 Sep 6]. Available from: http://www.law.go.kr/lsInfoP.do?lsiSeq = 172762\&ancYd = 2 0150706\&ancNo $=13392 \&$ efYd $=20150706 \&$ nwJoYnInfo $=$ N\&ef Gubun $=$ Y\&chrClsCd $=010202 \# 0000$ (Korean).

6. Dongkuk University. Development of educational course and training manual for field epidemiologist training program during 20112015. Cheongju: Korea Centers for Disease Control and Prevention; 2011, p. 2-211 (Korean).

7. Sihn KH. Research on endemic diseases and Japanese colonial rule: focusing on the emetine poisoning accident in Yeongheung and Haenam counties in 1927. Uisahak 2009;18:173-188 (Korean).

8. Governor-General of Korea. The chosun rules on Committee for Infectious and Endemic Diseases; 1920 Jul 14. Seoul: GovernorGeneral of Korea (Japanese).

9. Centers for Disease Control and Prevention. Epidemic intelligence service [cited 2017 Sep 6]. Available from: http://www.cdc.gov/eis.

10. National Law Information Center. Act for Prevention and Control of Communicable Disease; 2012 [cited 2017 Sep 6]. Available from: http://www.law.go.kr/lsInfoP.do?lsiSeq = 133300\&ancYd = 2 0130322\&ancNo $=11645 \&$ efYd $=20130923 \&$ nwJoYnInfo $=$ N\&ef Gubun $=$ Y\&chrClsCd $=010202 \# 0000$ (Korean).

11. Korea Centers for Disease Control and Prevention. Guideline for control and management of communicable diseases. Cheongju: Korea Centers for Disease Control and Prevention; 2015, p. 3-123 (Korean).

12. National Law Information Center. Enforcement Decree for Prevention and Control Communicable Disease; 2015 [cited 2017 Sep 6]. Available from: http://www.law.go.kr/lsSc.do?menuId =0 \&subMenu $=1 \&$ query = $\% \mathrm{EA} \% \mathrm{~B} 0 \% 90 \% \mathrm{EC} \% 97 \% \mathrm{BC} \% \mathrm{~EB} \% \mathrm{~B} 3 \%$ 91\#undefined (Korean).

13. Catholic University of Korea. A study on efficient field epidemiologist management system in Korea. Seoul: Korea Centers for Disease Control and Prevention; 2010, p. 1-141 (Korean).

14. Kwon GY, Moon S, Kwak W, Gwack J, Chu C, Youn SK. Epidemic intelligence service officers and field epidemiology training program in Korea. Osong Public Health Res Perspect 2013;4:215-221.

15. Hanyang University. Development of supervising system for field epidemiology training program. Seoul: Korea Centers for Disease Control and Prevention; 2009, p.1-56 (Korean). 